\title{
DNA-NUCLEAR MATRIX INTERACTIONS AND IONIZING RADIATION SENSITIVITY
}

\author{
Jeffrey L. Schwartz' and Andrew T.M. Vaughan \\ Biological and Medical Research Division, Argonne National Laboratory, Argonne, Illinois 60439, \\ U.S.A., and the Department of Radiation and Cellular Oncology, The University of Chicago, \\ Chicago, Illinois 60637, U.S.A. (J.L.S.); Department of Radiotherapy, Loyola University, Hines, \\ Illinois 60141, U.S.A. (A.T.M.V.)
}

\section{DISCLAIMER}

\begin{abstract}
This report was prepared as an account of work sponsored by an agency of the United States Government. Neither thi United States Government nor any agency thereof, nor any of their employees, makes any warranty, express or implied, or assumes any legal liability or responsibility for the accuracy, completeness, or usefulness of any information, apparatus, product, or process disclosed, or represents that its use would not infringe privately owned rights. Reference herein to any specific commercial product, process, or service by trade name, trademark, manufacturer, or otherwise does not necessarily constitute or imply its endorsement, recommendation, or favoring by the United States Government or any agency thereof. The views and opinions of authors expressed herein do not necessarily state or reflect those of the United States Government or any agency thereof.
\end{abstract}

Running Title: MARs and Radiation Sensitivity

Key words: Radiation sensitivity, DNA nuclear matrix, DNA repair, Chromosome aberrations

\footnotetext{
${ }^{1}$ Address reprint requests to J. L. Schwartz, Biological and Medical Research Division, Argonne National Laboratory, 9700 South Cass Avenue, Argonne, Illinois 60439-4833, U.S.A.

Corresponding author: J. L. Schwartz, Biological and Medical Research Division, Argonne National Laboratory, 9700 South Cass Avenue, Argonne, Illinois 60439-4833. U.S.A.; telephone (708) 252-3919, facsimile (708) 252-3387.
} 
Ionizing radiation produces primarily deletion mutations in exposed mammalian cells (Breimer, 1988; DeMarini et al., 1989; Sankaranarayanan, 1991). The kinetics of gene and chromosome mutation induction and the nature of the genetic changes suggest that these mutations develop from the recombination of two DNA double-strand breaks. Recombination requires DNA double-strand breaks to be ir close spatial and temporal proximity. As chromosome structure will determine the proximity of DNA sequences, it should influence the types of recombinations that can occur. In addition, recent studies suggest that chromosome structure, and in particular, DNA supercoiling, will also influence recombination frequency.

\section{Inherent Radiation Sensitivity and DNA Supercoil Unwinding}

The DNA in chromosomes is organized in many different levels (Nelson et al., 1986). At one level of organization, the DNA exists as a supercoiled loop attached to a protein structure, the DNA-nuclear matrix. When breaks are induced in this supercoiled loop, the loop relaxes and unwinds. Analyses of many different rodent and human cell lines (including Chinese hamster V79 cells [Olive, 1992; Gordon et al., 1990], mouse L5178y cells [Kapiszewska et al., 1989], human tumor cell lines [Schwartz and Vaughan, 1989], cell lines from patients with ataxia telangiectasia [Taylor et al, 1991], and the radiosensitive Chinese hamster ovary $[\mathrm{CHO}$ ] cell line xrs-5 [Schwartz et al, 1990, in press]) have shown an association between inherent radiation sensitivity and the ability of these loops to relax and unwind. The evidence for this association comes from DNA neutral filter elution, alkaline unwinding, and nucleoid-based assays of DNA damage (reviewed in Olive. 1992).

The neutral filter elution assay (Bradley and Kohn, 1979) measures the amount of DNA which elutes from cells lysed on a filter. It is used to estimate DNA double-strand break frequency. The assumption is that the rate at which DNA elutes depends on the 
size of DNA fragments and therefore on DNA break frequency. After low dose exposures, radioresistant cell lines show reduced rates and extents of DNA elution as compared to radiosensitive cells (Schwartz et al., 1991; Olive, 1992), suggesting that radioresistant cells are more resistant to DNA double-strand break induction than sensitive cells. However, no difference in break induction is seen after high dose exposures, and other independent measures of DNA double-strand break induction usually fail to detect differences between radioresistant and radiosensitive cell lines in DNA break induction (Olive, 1992). Wlodek and Olive (1990) have suggested that the reduced rate of DNA elution seen after low dose exposures in radioresistant cell lines is due to some residual protein structure which limits DNA unwinding and therefore DNA elution under the conditions used in the assay. This model is supported by the observation that differences between resistant and sensitive cells in elution rates can be seen even in unirradiated samples (Schwartz et al. 1991).

Evidence for constraints to DNA unwinding in radioresistant cells is also seen with the alkaline unwinding assay. In the alkaline unwinding assay (Ahnstrom, 1973), the amount of single-stranded DNA that forms when cells are lysed and denatured under alkaline condition is quantified. Single-stranded regions of the genome form when the DNA unwinds at sites of single-strand breaks. The relative amount of single-stranded DNA should therefore be directly related to the number of DNA single-strand breaks. Following radiation exposure, less single-stranded DNA is found in radioresistant cells than in radiosensitive cells (Olive et al, 1986; Olive, 1992; Schwartz et al, 1992) which would suggest fewer induced breaks. However, as mentioned above, other independent assays of DNA breaks find that sensitive and resistant cells do not differ in radiationinduced break frequencies (Olive, 1992). Therefore the reduced amounts of single- 
stranded DNA in radioresistant cells must reflect some constraint to DNA unwinding in these cells. This constraint is also seen in unirradiated cells (Schwartz et al., 1992).

Perhaps the best evidence for an association between radiation sensitivity and DNA supercoil unwinding comes from studies with nucleoids. Nucleoids are nuclei isolated such that most of the proteins have dissociated from the cell and what remains are intact supercoiled DNA loops attached to the nuclear matrix (Cook and Brazell, 1975; Cook et al. 1976). DNA strand breaks induce relaxation and unwinding of the supercoils, which are seen as increases in nucleoid size. This can be detected by sedimentation assay (Cook and Brazell, 1975), microscopic analysis (Roti Roti and Wright, 1987), or flow cytometric analysis (Milner et al. 1987). Smaller increases in nucleoid size are seen in radioresistant cell lines following lonizing radiation exposure than in radiosensitive cell lines (Gordon et al, 1990; Kapiszewska et al., 1989; Milner et al., 1987; Vaughan et al. 1992). Because radiosensitive and resistant cell lines are equally sensitive to break induction, the smaller increase in nucleoid size must reflect some constraint to unwinding in resistant cells. The structure responsible for the attachment of DNA to the nuclear matrix, the matrix attachment region (MAR), may be the structure controlling the extent of DNA unwinding, as differences in the nature of the MAR in resistant and sensitive cells have been reported (Schwartz and Vaughan, 1989; Vaughan et al., 1991).

\section{DNA-Nuclear Matrix Attachment and DNA/Chromosome Break Repair}

Limiting DNA unwinding may facilitate the repair of DNA strand breaks by keeping broken ends in closer proximity for a more rapid and accurate rejoining. The radioresistant cell lines mentioned above all rejoin DNA and chromosome breaks more rapidly than sensitive cells (Schwartz et al, 1988; Schwartz and Vaughan, 1989). This has been demonstrated with a variety of biochemical- and cytogenetic-based assays. The effect is only on the kinetics of break rejoining, as there is no evidence for a reduced 
capacity to rejoin breaks in most of these radiosensitive cells. The rate of rejoining also appears closely linked to the frequency of radiation-induced intra- and interchromosome exchanges. Radioresistant cell lines show smaller frequencies of interstitial chromosome deletions, dicentrics, and rings following radiation exposure. Thus, the constraint to DNA unwinding is associated with faster rates of DNA/chromosome break rejoining and reduced frequencies of intra- and interchromosomal exchanges in radioresistant cells.

The repair of DNA double-strand breaks is a complex process involving both exonuclease and DNA polymerase activities. One early event that follows break induction is the modification of proteins near the break site, which opens up the chromatin structure and initiates unwinding of DNA supercoiled loops. This unwinding may extend to adjacent loops (Mullenders et al., 1983). An analogous situation is found in transcribing regions of the genome where RNA polymerases drive DNA unwinding.

Recently, it has been shown that the MAR in actively transcribing regions of the genome may exist in a base-unpaired or cruciform-like structure (Kohwi-Shigematsu and Kohwi, 1990; Leonard and Patient, 1991; Bode et al. 1992). This structure tends to be more resistant to endonuclease digestion and has a greater affinity for the nuclear matrix. It has been suggested that this structure insulates transcribing regions of the genome from adjacent nontranscribing regions by preventing the unwinding of adjacent loops. Their open loop structure may also provide sites for transcription factors and polymerases to bind, and the torsional energy stored at these sites may be useful for driving gene transcription.

This open loop MAR structure could also act to insulate a radiation-damaged loop" from the rest of the genome, preventing the unwinding of adjacent loops and helping to maintain DNA ends in closer proximity. The closer proximity might lead to faster break rejoining and fewer intra- and interchromosomal exchanges. These open loop MAR 
configurations might also provide a recognition site at which repair proteins collect, which would facilitate repair by placing the required proteins close to the damaged site. and the torsional energy stored at this site could drive some of the enzymatic repair reactions as well.

This model suggests that differences in radiation sensitivity should be associated with alterations in gene expression. In fact, in the cell systems mentioned above, radiation sensitivity is just one aspect of a complex phenotype that distinguishes resistant and sensitive cell lines. Such a model also suggests that actively transcribed regions of the genome should be more resistant to radiation-induced change than nontranscribed regions. And, as the MARs are dynamic structures showing both tissuespecific and transformation-related alterations (Pienta and Coffey, 1992; Dickinson et al. 1992), one would predict that tissue-specific and transformation-related alterations in radiation sensitivity will reflect MAR alterations.

\section{Conclusion}

The association between inherent ionizing radiation sensitivity and DNA supercoil unwinding in mammalian cells suggests that the DNA-nuclear matrix attachment region (MAR) plays an important role in radiation response. In radioresistant cells, the MAR structure may exist in a more stable, open configuration, limiting DNA unwinding following strand break induction and maintaining DNA ends in close proximity for more rapid and accurate rejoining. In addition, the open configuration at these matrix attachment sites may serve to facilitate rapid DNA processing of breaks by providing (1) sites for repair proteins to collect and (2) energy to drive enzymatic reactions. 


\section{Acknowledgments}

This work was supported by the U.S. Department of Energy under contract No. W-31-109-ENG-38 and grant No. DE-FG02-88ER60661, by grants CA 42596 (JLS) and CA55840 (ATMV) from the NCI, The Center for Radiation Therapy, and a Faculty Research Award from the American Cancer Society (JLS). 


\section{References}

Ahnstrom G, Erixon K (1973): Radiation-induced strand breakage in DNA from mammalian cells: Strand separation in alkaline solution. Int $J$ Radiat Biol 23:285-289.

Bode J, Kohwi Y, Dickinson L, Joh T, Klehr D, Mielke C, Kohwi-Shigematsu T (1992): Biological significance of unwinding capability of nuclear matrix-associating DNAs. Science 255:195-197.

Bradley MO, Kohn KW (1979): X-ray induced DNA double-strand break production and repair in mammalian cells as measured by neutral filter elution. Nuc Acids Res 7:793-804.

Breimer LH (1988): Ionizing radiation-induced mutagenesis. $\mathrm{Br} \mathrm{J}$ Cancer 57:6-18.

Cook PR, Brazell IA (1975): Supercoils in DNA. J Cell Sci 19:261-279.

Cook PR, Brazell IA, Jost E (1976): Characterization of nuclear structures containing superhelical DNA. J Cell Sci 22:303-324.

DeMarini DM, Brockman HE, de Serres FJ, Evans HH, Stankowski LF Jr, Hsie AW (1989): Specific-locus mutations induced in eukaryotes (especially mammalian cells) by radiation and chemicals: a perspective. Mutat Res 220:11-29.

Dickinson LA, Joh T, Kohwi Y, Kohwi-Shigematsu T (1992): A tissue-specific MAR/SAR DNA-binding protein with unusual binding site recognition. Cell 70:631-645.

Gordon DJ, Milner AE, Beaney RP, Grdina DJ, Vaüghan ATM (1990): The increase in radioresistance of V79 cells cultured as spheroids is correlated to changes in nuclear morphology. Radiat Res 121:174-179. 
Kapiszewska M, Wright WD, Lange CS, Roti Roti JL (1989): DNA supercoiling changes in nucleoids from irradiated L5178-S and -R cells. Radiat Res 119:569-575. Kohwi-Shigematsu T, Kohwi Y (1990): Torsional stress stabilizes extended base unpairing in suppressor sites flanking immunoglobulin heavy chain enhancer. Biochemistry 29:9551-9560.

Leonard MW, Patient RK (1991): Evidence for torsional stress in transcriptionally activated chromatin. Molec Cell Biol 11:6128-6138.

Milner AE, Vaughan ATM, Clarke IP (1987): Measurement of DNA damage in mammalian cells using flow cytometry. Radiat Res 110:108-117.

Mullenders LHF, van Zeeland AA, Natarajan AT (1983): Comparison of DNA loop size and super-coiled domain size in human cells. Mutat Res 112:245-252 . Nelson WG, Pienta KJ, Barrack ER, Coffey DS (1986): The role of the nuclear matrix in the organization and function of DNA. Ann Rev Biophys Chem $15: 457-475$.

Olive PL (1992): DNA organization affects cellular radiosensitivity and detection of initial DNA strand breaks. Int J Radiat Biol 62:389-396.

Olive PL, Hilton J, Durand RE (1986): DNA conformation of Chinese hamster V79 cells and sensitivity to ionizing radiation. Radiat Res 107:115-124.

Pienta KJ, Coffey DS (1992): Nuclear-cytoskeletal interactions: Evidence for physical connections between the nucleus and cell periphery and their alterations by transformation. J Cell Biochem 49:357-365.

Roti Roti JL, Wright WD (1987): Visualization of DNA loops in nucleoids from HeLa cells: Assays for DNA damage and repair. Cytometry 8:461-467. 
Sankaranarayanan K (1991): Ionizing radiation and genetic risks. III. Nature of spontaneous and radiation-induced mutations in mammalian in vitro systems and mechanisms of induction of mutations by radiation. Mutat Res 258:75-97.

Schwartz JL, Vaughan ATM (1989): Association among DNA/chromosome break rejoining rates, chromatin structure alterations, and radiation sensitivity in human tumor cell lines. Cancer Res 49:5054-5057.

Schwartz JL, Rotmensch J, Giovanazzi SM, Cohen MB, Weichselbaum RR (1988): Faster repair of DNA double-strand breaks in radioresistant human tumor cells. Int J Radiat Oncol Biol Phys 15:907-912.

Schwartz JL, Shadley J, Jaffe DR, Whitlock J, Rotmensch J, Cowan JM, Gordon DJ, Vaughan ATM (1990): Association between radiation sensitivity, DNA repair. and chromosome organization in the Chinese hamster ovary cell line xrs-5. In Mendelsohn ML, Albertini RJ (eds): "Mutation and the Environment, Part B. Basic Mechanisms." New York: Wiley-Liss, Inc, pp. 255-264.

Schwartz JL, Mustafi R, Beckett MA, Czyzewski EA, Farhangi E, Grdina DJ, Rotmensch J, Weichselbaum RR (1991): Radiation-induced DNA doublestrand break frequencies in human squamous cell carcinoma cell lines of different radiation sensitivities. Int $\mathrm{J}$ Radiat Biol 59:1341-1352.

Schwartz, JL, Moan E, Mustafi R, Fink L, Yasui LS (1992): Chromatin structure alterations in xrs-5 cells detected by alkaline unwinding. Mutat Res 282:13-17. 
Schwartz JL, Cowan JM, Moan E, Sedita BA. Stephens J, Vaughan ATM (in press): Metaphase chromosome and nucleoid differences between CHO-K1 and its radiosensitive derivative xrs-5. Mutagenesis.

Taylor YC, Duncan PG, Zhang X, WNight WD (1991): Differences in the DNA supercoiling response of irradiated cell lines from ataxia-telangiectasia versus unaffected individuals. Int J Radiat Biol 59:359-371.

Vaughan ATM, Milner AM, Gordon DG, Schwartz JL (1991): Interaction between ionizing radiation and supercoiled DNA within human tumor cells. Cancer Res 51:3857-3861.

Wlodek D, Olive PL (1990): Physical basis for detection of DNA double-strand breaks using neutral filter elution. Radiat Res 124:326-333. 

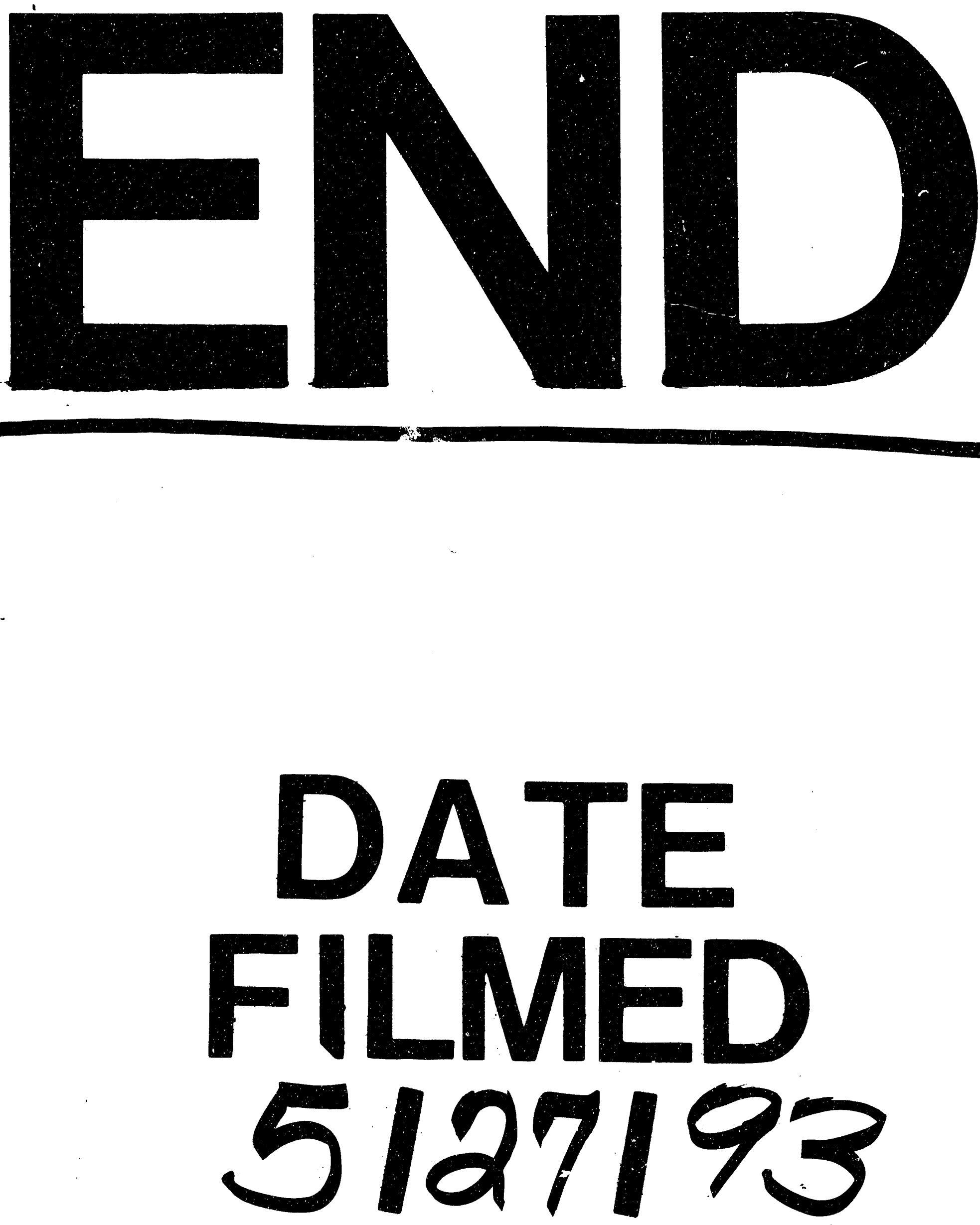